\title{
Adesão de Salmonella Enteritidis envolvida em surtos alimentares sob diferentes superfícies e condições ambientais
}

Salmonella Enteritidis adhesion involved in food outbreaks under different surfaces and environmental conditions

\author{
A. P. de Oliveira ${ }^{1 *}$; B. Webber ${ }^{2}$; E. S. Pottker ${ }^{2}$; L. Daroit ${ }^{3}$; L. R. dos Santos ${ }^{1}$; L. \\ B. Rodrigues ${ }^{1}$ \\ ${ }^{1}$ Programa de Pós-Graduação em Ciência e Tecnologia de Alimentos, Universidade de Passo Fundo, 99052-900, \\ Passo Fundo, RS, Brasil. \\ ${ }^{2}$ Programa de Pós Graduação em Ciências Veterinárias, Universidade Federal do Rio Grande do Sul, 91540-000, \\ Porto Alegre, RS, Brasil. \\ ${ }^{3}$ Departamento de Estatística, Instituto de Ciências Exatas e Geoeconômicas, Universidade de Passo Fundo, 99052 - \\ 900, Passo Fundo, RS, Brasil. \\ *amauri_po@hotmail.com
}

(Recebido em 18 de setembro de 2019; aceito em 08 de novembro de 2019)

\begin{abstract}
Salmonella Enteritidis é capaz de formar biofilmes no ambiente de processamento de alimentos podendo levar a surtos de doenças transmitidas por alimentos. Neste trabalho, avaliou-se a capacidade da $S$. Enteritidis formar biofilme em corpos de prova de aço inoxidável, polietileno e poliuretano a $3 \pm 1^{\circ} \mathrm{C}, 9 \pm 1^{\circ} \mathrm{C}$, $25 \pm 1^{\circ} \mathrm{C}, 36 \pm 1^{\circ} \mathrm{C}$ e $42 \pm 1^{\circ} \mathrm{C}$, após $0,4,8,12$ e 24 horas de incubação. Foram realizados testes com o uso de água a $45^{\circ} \mathrm{C}$ e a $85^{\circ} \mathrm{C}$, e com soluções de ácido peracético e amônia quaternária para remoção dos biofilmes. Ambas as cepas aderiram no aço inoxidável, no polietileno e no poliuretano, e em todas as temperaturas de exposição, inclusive a $3^{\circ} \mathrm{C}$ e $9^{\circ} \mathrm{C}$. O ácido peracético revelou-se o melhor tratamento na remoção dos biofilmes. De maneira geral, os resultados demonstraram que esses materiais, utilizados na indústria de alimentos, propiciaram a aderência das $S$. Enteritidis nas diferentes condições ambientais. Os resultados são importantes para o desenvolvimento de estratégias de controle de biofilmes na indústria, já que a presença desse microrganismo aderido pode comprometer a qualidade do alimento processado e consequentemente ter impacto na saúde pública.
\end{abstract}

Palavras-chave: biofilmes, superfícies, Salmonella Enteritidis.

Salmonella Enteritidis is able to form biofilms in food processing environment and can lead to foodborne disease outbreaks. In this work, we evaluated the ability of $S$. Enteritidis to form biofilm in stainless steel, polyethylene and polyurethane specimens at $3 \pm 1^{\circ} \mathrm{C}, 9 \pm 1^{\circ} \mathrm{C}, 25 \pm 1^{\circ} \mathrm{C}, 36 \pm 1^{\circ} \mathrm{C}$ and $42 \pm 1^{\circ} \mathrm{C}$, after $0,4,8,12$ and 24 hours incubation. Tests were performed using water at $45^{\circ} \mathrm{C}$ and $85^{\circ} \mathrm{C}$, and with solutions of peracetic acid and quaternary ammonia to remove biofilms. Both strains adhered to stainless steel, polyethylene and polyurethane, and at all exposure temperatures, including $3^{\circ} \mathrm{C}$ and $9^{\circ} \mathrm{C}$. Peracetic acid proved to be the best treatment for biofilm removal. In general, the results showed that these materials, used in food industry, provided adhesion of $S$. Enteritidis under different environmental conditions. The results are important for development of biofilm control strategies in industry, since the presence of this adhered microorganism may compromise the quality of processed food and consequently have an impact on public health.

Keywords: biofilms, surfaces, Salmonella Enteritidis.

\section{INTRODUÇÃO}

A Salmonella é uma das bactérias que mais causam doenças transmitidas por alimentos (DTA) em todo o mundo, estando relacionada frequentemente em surtos de origem alimentar, geralmente associados ao consumo de carne de aves e ovos, acarretando em prejuízos econômicos em vários países [1,2]. Quando capazes de formar biofilmes em superfícies de contato, possuem maior chance de transmissão aos alimentos processados [3].

Por estes motivos, o controle da formação de biofilmes é importante para a segurança dos alimentos, devido à adesão das bactérias em superfícies e utensílios em contato com os alimentos 
e sua difícil remoção com agentes sanitizantes. Como estes biofilmes liberam células planctônicas, que são células que se desprendem dos biofilmes, estas células livres contaminam o alimento, estando os biofilmes associados aos surtos de doenças alimentares [3].

Dos 598 surtos de DTA notificados no Brasil em 2017, com 9.426 doentes, 1.439 hospitalizados e 12 óbitos relacionados, dentre os agentes etiológicos identificados como únicos responsáveis pelos surtos confirmados laboratorialmente (89 surtos), está a Salmonella spp. $(14,6 \% / 13$ surtos) [2].

A $S$. Enteritidis (SE) é o principal sorovar isolado de humanos e alimentos e um dos principais isolados em animais, rações e amostras ambientais, além de ser um grande causador de infecções alimentares [1, 2]. Por este motivo, avaliou-se a sua habilidade em formar biofilmes em superfícies de aço inoxidável, polietileno e poliuretano, em diferentes condições ambientais, assim como o agente de sanitização mais eficaz para a redução e/ou eliminação deste problema em abatedouros avícolas.

\section{MATERIAL E MÉTODOS}

\subsection{Amostras de Salmonella Enteritidis}

Foram analisadas duas amostras de Salmonella Enteritidis (SE), quanto à capacidade de adesão à superfícies comumente usadas na indústria de alimentos. As cepas de SE foram previamente isoladas e confirmadas geneticamente por Microarray pelo equipamento Check\&Trace (RBiopharm AG, Darmstadt, Germany). Ambas as cepas são provenientes de surtos, sendo uma isolada de fezes (coprocultura), identificada como SE 24 e a outra isolada de maionese com batatas, identificada como SE 69.

\subsection{Preparação de corpos de prova}

Foram utilizados, como corpos de prova, superfícies de aço inoxidável AISI 316, polietileno e poliuretano, com $1 \mathrm{~cm}^{2}$ de diâmetro e $0,1 \mathrm{~cm}$ de espessura. Os materiais utilizados para a preparação dos corpos de prova foram obtidos do ambiente de processamento de cortes de aves. Os corpos de prova foram limpos manualmente com esponja, água e detergente líquido neutro, enxaguados com água destilada, imersos em álcool etílico $70 \%$ (v/v) por 1 hora a temperatura ambiente, enxaguados mais uma vez e esterilizados em autoclave a $121^{\circ} \mathrm{C}$ por 30 minutos.

\subsection{Testes de adesão de Salmonella Enteritidis}

Para a avaliação de adesão de SE, os corpos de prova foram colocados individualmente em microplacas estéreis de poliestireno com 12 poços (Nest®Biotech Co. Ltd, Rahway, NJ, USA). Foi adicionado $2,75 \mathrm{~mL}$ de caldo triptona de soja sem glicose (TSB without glucose, Difco® Laboratories, Sparks, MD, EUA) e $250 \mu \mathrm{L}$ de culturas individuais de cada SE, com aproximadamente $10^{3}$ UFC.mL ${ }^{-1}$ em cada poço. Esta população foi verificada, em todo o experimento, por semeadura em placas contendo Ágar Padrão de contagem (PCA, HiMedia ${ }^{\circledR}$ Laboratories, Mumbai, Índia).

Os corpos de prova de aço inoxidável, polietileno e poliuretano foram imersos na cultura de cada microrganismo (SE 24 e SE 69) e incubados a $42 \pm 1^{\circ} \mathrm{C}, 36 \pm 1^{\circ} \mathrm{C}, 25 \pm 1^{\circ} \mathrm{C}, 9 \pm 1^{\circ} \mathrm{C}$ e $3 \pm 1^{\circ} \mathrm{C}$, simulando as temperaturas do ambiente de processamento, ótimas dos microrganismos e de termotolerância, e avaliados nos tempos $0,4,8,12$ e 24 horas, simulando os períodos para higiene operacional e pré-operacional em abatedouros de aves em triplicata $[4,5]$.

Nos tempos determinados, os cupons foram removidos dos meios de cultivo com o auxílio de pinças esterilizadas, imersos em $5 \mathrm{~mL}$ de Água Peptonada $0,1 \%$ (AP, HiMedia ${ }^{\circledR}$ Laboratories, Mumbai, Índia), por 1 minuto, para a remoção de células planctônicas, colocados em tubos com Água Peptonada 0,1\%, e sonicados por 10 minutos em banho de ultrassom (frequência de $40 \mathrm{kHz}$ e potência de $81 \mathrm{~W}$ ) para desadesão de células sésseis [6]. Cinco gotas de $10 \mu \mathrm{L}$ de cada diluição foram inoculadas em placa de Petri contendo Ágar PCA, utilizado o método de contagem em gota (drop plate) e incubadas por 24 horas a $37 \pm 1^{\circ} \mathrm{C}$. 
Para o cálculo dos resultados, foi utilizada a seguinte fórmula: UFC.cm ${ }^{-2}=(\mathrm{VD} / \mathrm{VA})$. Av. D/A, em que VD foi o volume do diluente usado no enxágue $(5 \mathrm{~mL})$, VA o volume da alíquota usada no plaqueamento $(0,05 \mathrm{~mL}$ ou $0,1 \mathrm{~mL})$, Av a média de contagem obtida nas placas (UFC), D a diluição utilizada na contagem, e A a área do corpo de prova $\left(2 \mathrm{~cm}^{2}\right)$ expressa em $\log 10$. UFC.cm ${ }^{2}[7,8]$.

\subsection{Avaliação dos procedimentos de higienização}

Após a retirada das células planctônicas, os corpos de prova foram colocados em $5 \mathrm{~mL}$ de água estéril e aquecida a $45^{\circ} \mathrm{C}$ ou $85^{\circ} \mathrm{C}$ por 3 minutos e em solução de ácido peracético a $0,5 \%$ (Kalykim®, Alvorada, RS) ou 1\% quaternária amônia (Kalykim®, Alvorada, RS, Brasil) por 5 minutos, e o controle era água estéril à temperatura ambiente.

Em seguida, os corpos de prova foram imersos em $5 \mathrm{~mL}$ de Água Peptonada 0,1\% com neutralizador universal $(0,2 \%$ de lecitina de soja, $2 \%$ de tween, $0,25 \%$ de tiossulfato de sódio, $0,1 \%$ de água peptonada e $1 \mathrm{~L}$ de água destilada) por 1 minuto, a fim de parar a ação do sanitizante $[8,9]$. Individualmente cada cupom foi colocado em tubos com $5 \mathrm{~mL}$ de Água Peptonada $0,1 \%$ e sonicados em banho de ultrassom para desadesão de células sésseis. O liquido remanescente foi inoculados em placa de ágar com a técnica da gota, como descrito anteriormente no item 2.3.

\subsection{Análise estatística}

A comparação das médias foi realizada com o teste de Tukey a 5\% de probabilidade, e os resultados foram analisados por variância $[10,11]$.

\section{RESULTADOS E DISCUSSÃO}

\subsection{Adesão nas diferentes superfícies}

Houve adesão de SE no aço inoxidável, no polietileno e no poliuretano. Entretanto, houve maior adesão no polietileno em ambas as amostras, conforme a Tabela 1.

Tabela 1: Adesão de Salmonella Enteritidis sob diferentes superfícies.

\begin{tabular}{cccc}
\hline \multirow{2}{*}{ CEPA } & \multicolumn{3}{c}{ SUPERFÍCIES* } \\
\cline { 2 - 4 } & Aço inoxidável & Polietileno & Poliuretano \\
\hline SE 24 & $6,19 \mathrm{Aa}$ & $7,12 \mathrm{Ba}$ & $6,50 \mathrm{Aa}$ \\
SE 69 & $6,22 \mathrm{ABa}$ & $6,56 \mathrm{ABb}$ & $5,94 \mathrm{Ab}$ \\
\hline
\end{tabular}

* Resultados em $\log _{10}$.UFC.cm ${ }^{-2}$. As médias seguidas das mesmas letras maiúsculas nas linhas, e das mesmas letras minúsculas nas colunas, não diferem entre si pelo teste de Tukey $(\mathrm{P}>0,05)$.

A adesão de microrganismos a uma superfície está intimamente relacionada com as propriedades do material testado. Relatos têm demonstrado que a Salmonella consegue formar biofilmes em superfícies abióticas, como plástico, borracha, cimento, vidro e aço inoxidável [9, $12,13,14,15,16]$.

$\mathrm{Na}$ indústria de alimentos, o aço inoxidável tem sido o material mais utilizado por ter maior facilidade no processo de limpeza e desinfecção, quando comparado com a ampla variedade de polímeros. Porém, sua aplicabilidade é limitada em locais que são necessários materiais flexíveis $[4,17]$. Em abatedouros de frangos de corte, se destacam as esteiras de poliuretano e os utensílios fabricados com polietileno, principalmente as placas de corte [18, 19, 20].

Algo preocupante para a indústria de alimentos foi a capacidade das SE aderirem no aço inoxidável e formarem biofilme com a mesma capacidade de adesão ao poliuretano em ambas amostras. Vale ressaltar que por ser uma superfície menos irregular, o aço inoxidável possui maior adequação aos processos de higienização.

Houve maior adesão de SE no polietileno, possivelmente por ser uma superfície de natureza polimérica. Sinde e Carballo (2000) [21] afirmam que as placas de corte de polietileno apresentam superfícies irregulares, o que facilita a deposição de material orgânico dificultando a ação dos 
agentes desinfetantes. Em contrapartida, o polietileno é muito usado por ser atóxico e proporcionar menor desgaste das facas de corte [22].

Stepanovic et al. (2004) [23], observaram a formação de biofilme por Salmonella spp. e Listeria monocytogenes em superfície de plástico e ambos microrganismos produziram biofilme. Ao observar o meio de crescimento, a Salmonella spp. produziu mais biofilme em meio mais limitado em nutrientes, enfatizando o uso do TSB sem glicose em nossa pesquisa. Rodrigues et al. (2009) [24] corroboram com estudos sobre a capacidade de desenvolvimento de biofilme por Salmonella spp. em ambiente sem glicose, observaram que nessas condições amostras de $S$. Heidelberg foram capazes de formar biofilme em poliestireno.

Os resultados demonstram que tanto o aço inoxidável, quanto o polietileno e o poliuretano, materiais presentes na indústria de alimentos, propiciaram a aderência de $S$. Enteritidis. Fato preocupante para a indústria de alimentos e para a saúde dos consumidores, devido à potencial contaminação cruzada durante o processamento de alimentos.

\subsection{Efeito das temperaturas na adesão de Salmonella Enteritidis}

Os abatedouros avícolas brasileiros que exportam seus produtos para a União Europeia (UE) devem garantir no resfriamento dos produtos temperatura de no máximo $4^{\circ} \mathrm{C}$ e na sala de cortes temperatura ambiente não superior a $10^{\circ} \mathrm{C}$, respeitando, assim, o regulamento técnico da inspeção tecnológica e higiênico-sanitária, conforme a Portaria n ${ }^{\circ} 210$ [25].

Partindo deste pressuposto, mimetizou-se as temperaturas preconizadas em abatedouros avícolas: $3 \pm 1^{\circ} \mathrm{C}$, temperatura de resfriamento; $9 \pm 1^{\circ} \mathrm{C}$, temperatura da sala de cortes para EU; $25 \pm 1^{\circ} \mathrm{C}$, temperatura ambiente; $36 \pm 1^{\circ} \mathrm{C}$, padrão ótimo para crescimento de mesófilos; e $42 \pm 1^{\circ} \mathrm{C}$, temperatura de enriquecimento seletivo para Salmonella, devido à termotolerância.

Ambas SE tiveram a capacidade de aderir nas temperaturas de $3^{\circ} \mathrm{C}, 9^{\circ} \mathrm{C}, 25^{\circ} \mathrm{C}, 36^{\circ} \mathrm{C}$ e $42^{\circ} \mathrm{C}$. No entanto, observou-se uma maior adesão da $S$. Enteritidis com o aumento das temperaturas de incubação, conforme a Tabela 2 e as Figuras 1 e 2.

Tabela 2: Adesão de Salmonella Enteritidis sob diferentes temperaturas.

\begin{tabular}{cccccc}
\hline \multirow{2}{*}{ CEPA } & \multicolumn{5}{c}{ TEMPERATURAS* } \\
\cline { 2 - 6 } & $\mathbf{3}^{\mathbf{0}} \mathbf{C}$ & $\mathbf{9}^{\mathbf{}} \mathbf{C}$ & $\mathbf{2 5}^{\circ} \mathbf{C}$ & $\mathbf{3 6}^{\mathbf{}} \mathbf{C}$ & $\mathbf{4 2}^{\mathbf{C}} \mathbf{C}$ \\
\hline SE 24 & $6,08 \mathrm{Aa}$ & $6,41 \mathrm{ABa}$ & $6,84 \mathrm{Ba}$ & $6,88 \mathrm{Ba}$ & $6,80 \mathrm{Ba}$ \\
SE 69 & $5,77 \mathrm{Aa}$ & $5,91 \mathrm{Ab}$ & $6,47 \mathrm{ABCa}$ & $6,81 \mathrm{BCa}$ & $6,23 \mathrm{ABCb}$ \\
\hline
\end{tabular}

* Resultados em $\log _{10}$.UFC.cm ${ }^{-2}$. As médias seguidas das mesmas letras maiúsculas nas linhas, e das mesmas letras minúsculas nas colunas, não diferem entre si pelo teste de Tukey $(\mathrm{P}>0,05)$. 


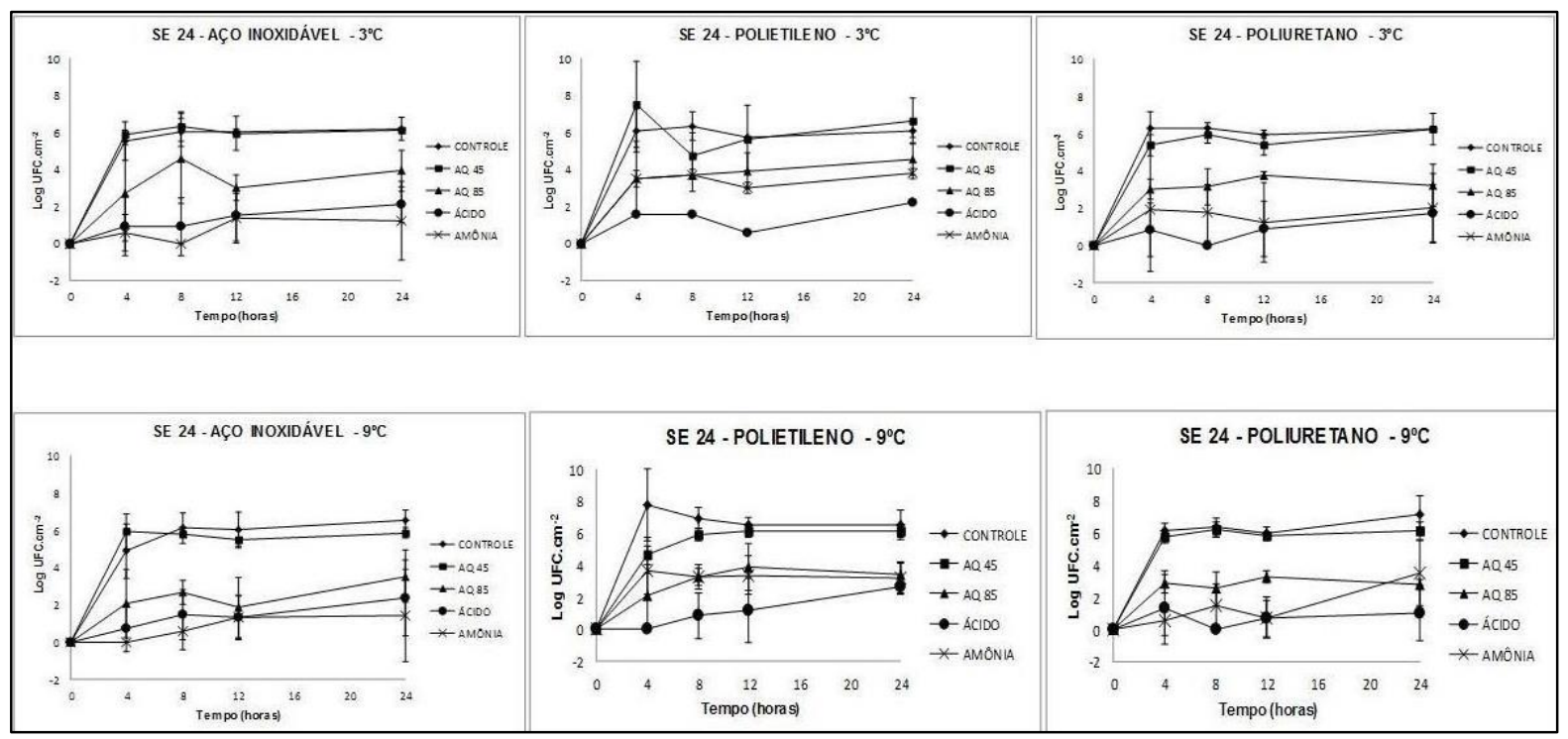

Figura 1: Adesão de Salmonella Enteritidis 24 em diferentes superfícies sob temperaturas de refrigeração e frente a procedimentos de higienização.

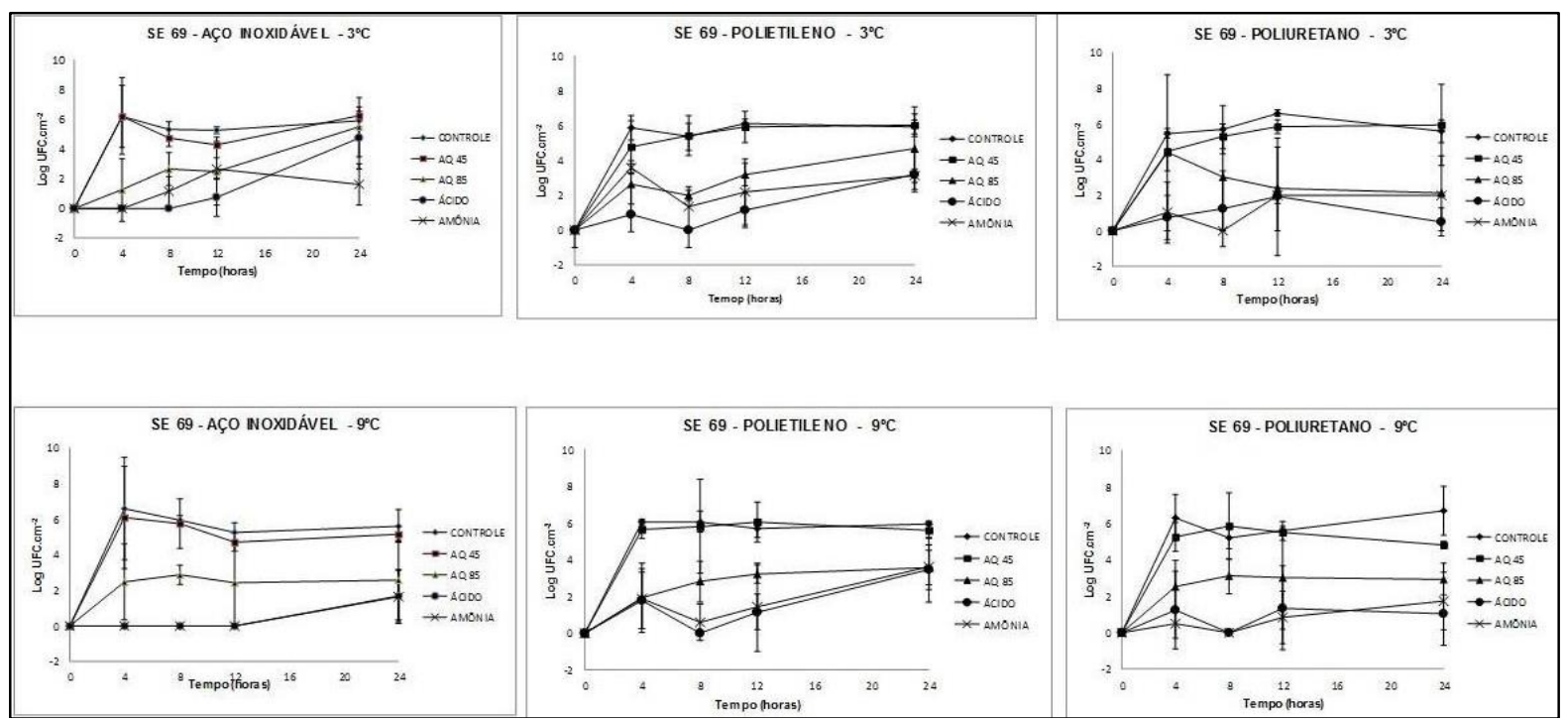

Figura 2: Adesão de Salmonella Enteritidis 69 em diferentes superfícies sob temperaturas de refrigeração e frente a procedimentos de higienização.

Enfatiza-se a adesão de $S$. Enteritidis na temperatura de $3^{\circ} \mathrm{C}$ nas superfícies de aço inoxidável, polietileno e poliuretano, descrita anteriormente como possível para crescimento de Salmonella spp. [26]. Fato este preocupante, uma vez que as temperaturas de refrigeração atuam na conservação dos alimentos inibindo o crescimento microbiano.

Morey e Singh (2012) [27] salientam que temperaturas baixas, como $4^{\circ} \mathrm{C}$ e $8^{\circ} \mathrm{C}$, foram fatores importantes na determinação da sobrevivência e crescimento de $S$. Typhimurium e $S$. Heidelberg. Em nosso estudo destaca-se, também, a importância da manutenção de alimentos a temperaturas de refrigeração o mais próximo possível de $0^{\circ} \mathrm{C}$, pois a adesão a $9^{\circ} \mathrm{C}$ foi semelhante à temperatura ótima na SE 24 e à temperatura ambiente e de termotolerância na SE 69.

Rode et al. (2007) [28] e Reuter et al. (2010) [29] citam que os microrganismos na forma de vida séssil adaptam-se melhor ao meio, e isso permite a sobrevivência e crescimento sob condições prejudiciais e estressantes. Os resultados reportados corroboram com esta possibilidade de desenvolvimento de biofilmes de SE em condições inóspitas de temperaturas baixas.

3.3 Efeito do tempo na adesão de Salmonella Enteritidis 
Os abatedouros avícolas devem ser limpos e sanificados após o término do processo produtivo. Esse processo é realizado no final do turno de abate, sendo conhecido como higiene préoperacional, e ocorre a cada 12 e 24 horas. Durante o processo produtivo, em tempos de 4 e 8 horas costuma-se realizar a chamada higiene operacional.

Ao mimetizar os tempos preconizados no processo de higienização operacional, 4 e 8 horas, e pré-operacional, 12 e 24 horas, ambas SE não revelaram diferença significativa na adesão de SE após 4, 8, 12 e 24 horas de incubação, conforme a Tabela 3.

Tabela 3: Adesão de Salmonella Enteritidis sob diferentes tempos.

\begin{tabular}{cccccc}
\hline \multirow{2}{*}{ CEPA } & \multicolumn{5}{c}{ TEMPOS* } \\
\cline { 2 - 6 } & 0 horas & 4 horas & 8 horas & 12 horas & 24 horas \\
\hline SE 24 & $0,00 \mathrm{Aa}$ & $6,57 \mathrm{Ba}$ & $6,65 \mathrm{Ba}$ & $6,66 \mathrm{Ba}$ & $6,53 \mathrm{Ba}$ \\
SE 69 & $0,00 \mathrm{Aa}$ & $6,56 \mathrm{Ba}$ & $5,99 \mathrm{Bb}$ & $6,08 \mathrm{Bb}$ & $6,32 \mathrm{Ba}$ \\
\hline
\end{tabular}

* Resultados em $\log _{10}$.UFC.cm ${ }^{-2}$. As médias seguidas das mesmas letras maiúsculas nas linhas, e das mesmas letras minúsculas nas colunas, não diferem entre si pelo teste de Tukey $(\mathrm{P}>0,05)$.

Ressalta-se a importância do processo de higiene operacional em intervalos de poucas horas durante o processo produtivo, evitando que resíduos aderidos se tornem fontes de contaminação, e não somente o término do processamento para que seja realizada apenas a higiene préoperacional. Parizzi e Andrade (2004) [30] salientam que o número de células aderidas nas superfícies aumentarão com o tempo de contato do microrganismo, consequentemente, quanto maior a taxa de contaminação mais prejudicada a higienização.

As falhas nos procedimentos de higienização permitem que os resíduos aderidos aos equipamentos e superfícies transformem-se em potencial fonte de contaminação. Sob determinadas condições, os microrganismos se aderem, interagem com as superfícies e iniciam crescimento celular [30].

\subsection{Tratamentos de higienização}

Entre os tratamentos testados o ácido peracético $0,5 \%$ se mostrou o melhor na remoção dos biofilmes nas três superfícies, em todas as temperaturas e tempos de adesão, seguido pela ação da amônia quaternária a $1 \%$, da água estéril aquecida a $85^{\circ} \mathrm{C}$ e da água estéril aquecida a $45^{\circ} \mathrm{C}$, conforme a Tabela 4. Nossos resultados corroboram ao relatado por Webber et al. (2019) [26], que obteve melhor redução de biofilmes em $S$. Enteritidis, de origem avícola, em diferentes superfícies com o uso do ácido peracético.

Tabela 4: Remoção de biofilmes de Salmonella Enteritidis provenientes de surtos de DTA, nas superfícies de aço inoxidável, polietileno e poliuretano frente a diferentes procedimentos de higienização.

\begin{tabular}{cccccc}
\hline & \multicolumn{5}{c}{ TRATAMENTOS* } \\
\cline { 2 - 6 } CEPA & CONTROLE & $\begin{array}{c}\mathbf{H 2 O} \\
\mathbf{4 5}^{\circ} \mathbf{C}\end{array}$ & $\begin{array}{c}\text { H2O } \\
\mathbf{8 5}^{\circ} \mathbf{C}\end{array}$ & $\begin{array}{c}\text { ÁCIDO } \\
\text { PEACÉTICO }\end{array}$ & $\begin{array}{c}\text { AMÔNIA } \\
\text { QUATERNÁRIA }\end{array}$ \\
\hline SE 24 & $6,60 \mathrm{Aa}$ & $6,18 \mathrm{Ba}$ & $2,86 \mathrm{Ca}$ & $1,18 \mathrm{Da}$ & $2,17 \mathrm{Ea}$ \\
SE 69 & $6,24 \mathrm{Ab}$ & $5,57 \mathrm{Bb}$ & $2,37 \mathrm{Cb}$ & $1,33 \mathrm{Da}$ & $1,69 \mathrm{Db}$ \\
\hline
\end{tabular}

* Resultados em $\log _{10}$.UFC.cm ${ }^{-2}$. As médias seguidas das mesmas letras maiúsculas nas linhas, e das mesmas letras minúsculas nas colunas, não diferem entre si pelo teste de Tukey $(\mathrm{P}>0,05)$.

Na Diretiva 471/2001 da UE, no teste de superfícies, o nível aceitável é até no máximo 10 UFC.cm ${ }^{-2}\left(1,5 \log _{10}\right.$ UFC.cm $\left.{ }^{-2}\right)$ de microrganismos mesófilos e 1 UFC.cm ${ }^{-2}\left(0,15 \log _{10}\right.$ UFC.cm $\left.{ }^{-2}\right)$ de enterobactérias. Os estabelecimentos habilitados à exportação para a União Europeia devem atender a esta diretiva [31]. Entretanto, para testes de superfícies em contato com alimentos, de acordo com a norma EN 13697:2001 da União Europeia, os procedimentos de sanitização devem realizar uma redução de no mínimo 4 log na contagem bacteriana $[15,32]$.

Ao avaliar a média de redução em todas as superfícies e tempos de incubação, na amostra SE 24 obteve-se uma redução de 5,42 $\log _{10}$ UFC.cm ${ }^{-2}$ após contato com o ácido peracético, 4,43 
$\log _{10} \mathrm{UFC} . \mathrm{cm}^{-2}$ com uso de amônia quaternária e $3,74 \log _{10} \mathrm{UFC} . \mathrm{cm}^{-2}$ com a água estéril a $85^{\circ} \mathrm{C}$. A SE 69 obteve redução de $4,91 \log _{10}$ UFC.cm ${ }^{-2}$ com o uso do ácido peracético, $4,55 \log _{10}$ UFC.cm ${ }^{-}$ 2 após o a amônia quaternária e $3,87 \log _{10} \mathrm{UFC} . \mathrm{cm}^{-2}$ após a água a $85^{\circ} \mathrm{C}$. Os sanitizantes demonstraram eficácia na redução dos biofilmes e o uso da água a $85^{\circ} \mathrm{C}$ ficou muito próximo da redução de 4 log exigida [32].

Vale ressaltar que a água estéril aquecida a $45^{\circ} \mathrm{C}$ não atendeu as recomendações para higienização de uma superfície conforme norma EN 13697:2001 [32], para ambas SE. Destacase a necessidade do uso de pressão junto com a água estéril aquecida a $45^{\circ} \mathrm{C}$, conforme Contreras et al. (2002) [33], para obter uma boa eficácia da etapa de pré-enxágue.

Silva et al. (2014) [34] e Sinde e Carballo (2000) [21] relatam a eficácia dos sanitizantes frente à $\mathrm{SE}$, e ressaltam que a redução da aderência depende das propriedades do material testado. Já Borowsky et al. (2006) [35] demonstraram a resistência de amostras de $S$. Typhimurium após 5 minutos de exposição aos sanitizantes, mas, após 15 minutos de contato nenhuma foi resistente.

A sobrevivência dos microrganismos à desinfecção é frequentemente associada com a presença de biofilmes em superfícies [36]. Os biofilmes constituem uma forma privilegiada de vida para as bactérias, e uma compreensão mais clara dos processos envolvido é crucial para o seu controle.

A melhor opção para a remoção de biofilmes de SE, em superfícies usadas comumente em abatedouros, é a utilização de ácido peracético como agente sanitizante e o uso da água aquecida a $85^{\circ} \mathrm{C}$ para os utensílios. Além disso, esses resultados salientam a necessidade de emprego de ação mecânica em conjunto à ação química na remoção dos biofilmes. Os resultados demonstraram a importância dos procedimentos de higiene, já que a formação de biofilme pode ocorrer em um curto período, o que enfatiza a necessidade de bons procedimentos de higienização durante todo o processamento de alimentos.

\section{CONCLUSÃO}

Salmonella Enteritidis foi capaz de aderir nas superfícies testadas, sendo o polietileno a superfície com maior adesão. A SE 24 e SE 69 aderiram em todas as temperatura, inclusive nas propícias para a conservação dos alimentos, $3^{\circ} \mathrm{C}$ e $9^{\circ} \mathrm{C}$. Comparando os sanitizantes testados, o ácido peracético foi o melhor tratamento na remoção de Salmonella Enteritidis.

\section{REFERÊNCIAS BIBLIOGRÁFICAS}

1. WHO-World Health Organization. Salmonella. 2016. Disponível em: <http://www.who.int/topics/salmonella/en/>. Acesso em: 20 fev. 2018.

2. BRASIL. Ministério da Saúde. Surtos de Doenças Transmitidas por Alimentos no Brasil Informe (2018). Disponível em: < http://portalarquivos2.saude.gov.br/images/pdf/2019/fevereiro/15/Apresenta---o-Surtos-DTA---Fevereiro-2019.pdf>. Acesso em: 20 jun. 2019.

3. Van Houdt R, Michiels CW. Biofilm formation and the food industry, a focus on the bacterial outer surface. J Appl Microbiol. 2010;109:1117-1131. doi:10.1111/j.1365-2672.2010.04756.x

4. Rossoni EMM, Gaylarde CC. Comparison of sodium hypoclorite and peracetic acid as sanitising agents for stainless steel food processing surfaces using epifluorescence microscopy. Int J Food Microbiol. 2000;61:81-85.doi.org/10.1016/S0168-1605(00)00369-X

5. Kusumaningrum HD, Riboldi G, Hazeleger WC, Beumer RR. Survival of foodborne pathogens on stainless steel surfaces and cross-contamination to foods. Int J Food Microbiol. 2003;83(3):227-236. doi:10.1016/s0168-1605(02)00540-8

6. Scherba G, Eigel RM, O'Brien WD. Quantitative assessment of the germicidal efficacy of ultrasonic energy. Appl Enviroml Microbiol. 1991;57:2079-2084. PubMed PMID: 1892396

7. Gibson H, Taylor JH, Hall KE, Holah JT. Effectiveness of cleaning techniques used in the food industry in terms of the removal of bacterial biofilms. J Appl Microbiol. 1999;87:41-48. doi:10.1046/j.13652672.1999.00790.x

8. ISO 18593:2012. (2012). Microbiology of food and animal feeding stuffs - Horizontal methods for sampling techniques from surfaces using contact plates and swabs. ABNT - Associação Brasileira de Normas Técnicas. 8 p.

9. Joseph B, Otta SK, Karunasagar IV. Biofilm formation by Salmonella spp. on food contact surfaces and their sensitivity to sanitizers. Int J Food Microbiol. 2001;64:367-372. doi:10.1016/s01681605(00)00466-9 
10. Assitat:Versão 7.7 beta. DEAG-CTRN-UFCG - Atualizado em 01 de abril de 2014. Disponível em: <www.assistat.com>. Acesso em: 20 fev. 2018.

11. Silva FAS. ASSISTAT: Versão 7.7 beta. DEAG-CTRN-UFCG - Atualizado em 01 de abril de 2014. Disponível em: <www.assistat.com>. Acesso em: 20 fev. 2018.

12. Solano C, Garcia B, Valle J, Berasain C, Ghigo JM, Gamazo C, Lasa I. Genetic analysis of Salmonella Enteritidis biofilm formation: critical role of celulose. Mol Microbiol. 2002;43(3):793-808. doi:/doi.org/10.1046/j.1365-2958.2002.02802.x

13. Prouty AM, Gunn JS. Comparative analysis of Salmonella enteric serovar Typhimurium biofilm formation in gallstones and on glass. Infect Immun. 2003;70(5):2640-2649. doi:10.1128/IAI.71.12.7154-7158.2003

14. Arnold JW, Yates IE. Interventions for control of Salmonella: clearance of microbial growth from rubber picker fingers. Poultry Sci. 2009;88(6):1292-1298. doi:10.3382/ps.2008-00391

15. Moretro T, Vestby LK, Nesse LL, Hannevik S, Koltarz K, Lansurd S. Evaluation of efficiency of disinfectants against Salmonella from the feed industry. J Appl Microbiol. 2009;106:1005-1012. doi.org/10.1111/j.1365-2672.2008.04067.x

16. O'Leary D, MCcabe EM.; Mccusker MP, Martins M, Fanning S, Duffy G. Microbiological study of biofilm formation in isolates of Salmonella enterica Typhimurium DT104 and DT104b cultured from the modern pork chain. International J Food Microbiol. 2013;161:36-43. Doi:10.1016/j.ijfoodmicro.2012.11.021

17. Holah JT, Thorpe RH. Cleanability in relation to bacterial retention on unused abraded domestic sink materials. J Appl Microbiol. 1990;69(4):599-608. doi:10.1111/j.1365-2672.1990.tb01554.x

18. Carpentier B. Sanitary quality of meat chopping board surfaces: a bibliographical study. Food Microbiol. 1997;14: 31-37. doi:10.1006/fmic.1996.0061

19. Steenackers H, Hermans K, Vanderleyden J,; Keersmaecker SCJ. Salmonella biofilms: An overview on occurrence, structure, regulation and eradication. Food Res Int. 2012;45:502-531. doi:10.1016/j.foodres.2011.01.038

20. Rodrigues LB, Santos LR, Rizzo NN, Tagliari VZ, Trenhago G, Oliveira AP, Ferreira D, Pilotto F, Nascimento VP. Salmonella and Listeria from Stainless Steel, Polyurethane and polyethylene Surfaces in the Cutting Room of a Poultry Slaughterhouse. Acta Sci Veterin. 2013;41:1-7.

21. Sinde E, Carballo J. Attachment of Salmonella sp. and Listeria monocytogenes to stainless steel, rubber and polytetrafluorethylene: the influence of free energy and the effect of commercial sanitizers. Food Microbiol. 2000;17(4):439-447.doi:10.1006/fmic.2000.0339

22. Oliveira FA, Brandelli A, Tondo EC. Antimicrobial resistance in Salmonella Enteritidis from foods involved in human salmonellosis outbreaks in southern Brazil. New Microbiolog. 2006;29:49-54.

23. Stepanovic S, Irkovic IC, Ranin L, Svabic-Vlahovic M. Biofilm formation by Salmonella spp. and Listeria monocytogenes on plastic surface. Lett Appl Microbiol. 2004;38:428-432.doi:10.1111/j.1472765x.2004.01513.x

24. Rodrigues LC, Santos LR, Rizzo NN, Tagliari VZ, Oliveira AP, Trenhago G, Rodegheri SC, Taglieti RM, Dickel EL, Nascimento VP. Hydrophobicity and biofilm formation on polystyrene by Salmonella Heidelberg isolated from a poultry slaughterhouse. Acta Sci Veterin. 2009;37:225-230.

25. Brasil. Ministério da Agricultura, Pecuária e Abastecimento. (1998). Portaria ${ }^{\circ} 210$, de 10 de novembro de 1998. Regulamento Técnico da Inspeção Tecnológica e Higiênico-Sanitária de Carne de Aves. Diário Oficial da União de 26 nov., seção 1, p. 226.

26. Webber B, Oliveira AP, Pottker, ES, Daroit L, Levandowski R, Santos LR, Nascimento VP, Rodrigues LB. Salmonella Enteritidis forms biofilm under low temperatures on different food industry surfaces. Ci Rural. 2019;49(7).doi:10.1590/0103-8478cr20181022

27. Morey A, Singh S. Low-Temperature Survival of Salmonella spp. in a Model Food System with Natural Microflora. Department of Poultry Science, Auburn University, Auburn, Alabama. Foodborne Pathog Dis. 2012;9(3).doi:10.1089/fpd.2011.1016

28. Rode TM, Langsrud S, Holck A, Moretro T. Different patterns of biofilm formation in Staphylococcus aureus under food-related stress conditions. Int J Food Microbiol. 2017;116:372-383. doi:10.1016/j.ijfoodmicro.2007.02.017

29. Reuter M, Mallett A, Pearson BM, Van Vliet AH. Biofilm formation by Campylobacter jejuni is increased under aerobic conditions. Appl Environm Microbiol. 2010;76:21222128.doi:10.1128/aem.01878-09

30. Parizzi SQF, Andrade NJ. Bacterial Adherence to Different Inert Surfaces Evaluated by Epifluorescence Microscopy and Plate Count Method. J Braz Arch Biol Techn. 2004;47:77-83.doi:10.1590/s151689132004000100011

31. União Europeia. Diretiva 2001/471/CE de 21 de junho de 2001. Regras para os controles regulares à higiene geral dos estabelecimentos. Comissão da Comunidades Europeias, Europa, 2001a. 
32. União Europeia. NS-EN 13697:2001: Quantitative Non-Porous Surface Test for the Evaluation of Bactericidal and / or Fungicidal Activity of Chemical Disinfectants used in Food, Industrial, Domestic and Institutional Areas. Test Method and equirements without Mechanical Action. Brussels, Belgium: European Committee for standardization. Europa, 2001b.

33. Contreras CJ, Bromberg R, Cipolli KMVAB, Miyagusku L. Higiene e sanitização na indústria de carnes e derivados. São Paulo: Varela, 2002. 181 p.

34. Silva CF, Gehlen SS, Webber B, Diedrich LN, Pilotto F, Santos LR, Tondo EC, Nascimento VP, Rodrigues LB. Biofilm Former Salmonella Enteritidis are Multiresistant to Antibiotics. Acta Sci Veterin. 2014;42:1-8.

35. Borowsky LM, Bessa MC, Cardoso MI, Avancini CAM. Sensibilidade e resistência de amostras de Salmonella Typhimurium isoladas de suínos abatidos no Rio Grande do Sul/Brasil frente aos desinfetantes químicos quaternário de amônio e iodofor. Cia Rural. 2006;36:76-79.doi:10.1590/s010384782006000500020

36. Bressler DC, Balzer M, Dannehl A, Flemming HC, Wingender J. Persistence of Pseudomonas aeruginosa in drinking-water biofilms on elastomeric material. Water Sci Technol. 2009;9:8187.doi:10.2166/ws.2009.026 